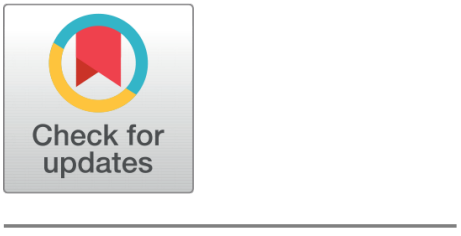

G OPEN ACCESS

Received: 04-04-2020

Accepted: 23-04-2020

Published: $10-06-2020$

Editor: Dr. Natarajan Gajendran

Citation: Salahuddin S, Mehar Q, Kazi H (2020) Factors influencing transfer of training: Empirical evidence from public sector schools Hyderabad Pakistan. Indian Journal of Science and Technology 13(18): 1796-1802. https://doi.org/ 10.17485/IJST/v13i18.51

* Corresponding author. Syed Salahuddin

Adjunct Assistant Professor, Department of Management Sciences, Isra University, Hyderabad, Pakistan

Associate professor, Department of Economics, Government S. S. Arts \& Science College, Hyderabad,

Pakistan

salahuddinpk@gmail.com

Funding: None

Competing Interests: None

Copyright: @ 2020 Salahuddin, Mehar, Kazi. This is an open access article distributed under the terms of the Creative Commons Attribution License, which permits unrestricted use, distribution, and reproduction in any medium, provided the original author and source are credited.

Published By Indian Society for Education and Environment (iSee)

\section{Factors influencing transfer of training: Empirical evidence from public sector schools Hyderabad Pakistan}

\author{
Syed Salahuddin ${ }^{1,2 *}$, Qamaruddin Mehar ${ }^{3}$, Hameedullah Kazi ${ }^{4,5}$ \\ 1 Adjunct Assistant Professor, Department of Management Sciences, Isra University, \\ Hyderabad, Pakistan \\ 2 Associate professor, Department of Economics, Government S. S. Arts \& Science College, \\ Hyderabad, Pakistan \\ 3 Associate Professor, Department of Management Sciences, Isra University, Hyderabad, \\ Pakistan \\ 4 Professor, Department of Electrical Engineering and Computer Sciences, Isra University, \\ Hyderabad, Pakistan \\ 5 Department of Management Sciences, Isra University, Hyderabad, Pakistan
}

\section{Abstract}

Aim/objectives: The aim of this research is, to examine the factors of training design that influence transfer of teachers training to the classrooms, in education sector of Pakistan where education sector is in the state of crisis. Methods/Statistical Analysis: For this research, primary data had been collected with the help of questionnaire; a sample of 500 trainee teachers was selected from public sector schools of Hyderabad Pakistan who attended the teachers training programs. Two variables of training design i.e. content validity and transfer design were analyzed using various statistical techniques like factor analysis, reliability analysis, correlation and multiple regression. Statistical software SPSS ver.22 was used for this purpose. Findings : The transfer design found to be the strongest factor effecting transfer of training with beta value 0.558 followed by perceived content validity with beta value 0.127 , both variables were found to have positive and significant impact on transfer of training. These two independent variables explained $41 \%$ variance in regression model. Findings of this research revealed that the training design plays a vital role in training and may predict the training transfer significantly. Originality and novelty: Primary data has been collected for this research. The findings of this research will fill the gap in the literature of training transfer in the education sector. Application: Outcomes of this study will pave way to the facilitation of the authorities of education sector as to, how teachers' training should be made useful by improving the components of training design.

Keywords: Teachers training; transfer of training; training design; education; Pakistan 


\section{Introduction}

Transfer of training (TOT) is the extent to which the skill and knowledge acquired during training is being applied to the workplace ${ }^{(1)}$. Transfer of training is very important for education sector like other sectors of society. Organizations around the world are investing a huge amount on training but the trainees are transferring a small percent of acquired skills to their workplace ${ }^{(2)}$. Training is supposed to be ineffective if it is not improving the performance of trainee ${ }^{(3)}$. The training transfer has become broadly recognized arena of research and practice ${ }^{(4)}$. Despite a lot of research on transfer of training ${ }^{(5-9)}$, least literature has been found regarding transfer of teachers' training in education sector. Education is no doubt has a significance around the globe ${ }^{(6)}$. It is one of the most important variable of economic development and human development index (HDI) ${ }^{(10)}$. Education is the most significant concern around the globe and the most important concern of education is teacher ${ }^{(6)}$. In spite of robust progress in education, substantial challenges still exist to attain worldwide education goal ${ }^{(11)}$. The scenario in Pakistani education paints an obnoxious and unpleasant portrait of education system in the sense of teacher's knowledge and teaching practice in the classroom ${ }^{(12)}$. However, recently the four provinces of Pakistan have increased education budget and are emphasizing on teachers training. The training and consultancy industry in Pakistan is involved in activities of training and its transfer but it seems that this industry is not considerably aware about the notion of training transfer and it appears that they are just increasing their income and not measuring $\mathrm{TOT}^{(13)}$. Public sector education carries severe concern in most of the countries. In the past few decades, Pakistan has witnessed much attention by its various governments on basic education quality through many facets, like improvement of infrastructure, curriculum, learning resources, involvement of community and preparation of better teachers. Among all these facets the education of teacher has been recognized as the most important variable $^{(14)}$. Government of Pakistan issues "Economic Survey of Pakistan" and "The Bulletin of Statistics" these cover almost all sectors of economy but there is no chapter on training transfer, the former one includes only a very little information regarding training in education. These facts show that in Pakistan a little priority is been given to training transfer ${ }^{(13)}$. Author in ${ }^{(15)}$ told that Pakistan is unable to implement educational policies due to political and financial constraint. In previous researches, many a researchers emphasized on the factors like characteristics or individualities of trainee, design of training and environment of workplace ${ }^{(1,8,12)}$. Among these many researches have studied training design by analyzing two variables i.e. perceived training content and transfer design. The training design refers to the extent to which the training is structured and delivered to the trainee so that he/she may be able to transfer it to their job ${ }^{(16)}$. Perceived content validity denotes to the trainee's judgment about the contents of training program and the extent of these contents reflects in the job requirement accurately ${ }^{(2)}$. Transfer design refers to how much the activities and exercises demonstrated during training are focused on their application to the $\mathrm{job}^{(8)}$. Still the answer is awaited about the effectiveness of TOT about the knowledge and skill acquired during the training that is being applied at the workplace ${ }^{(17)}$. Author in ${ }^{(18)}$ confirmed that the significance of content validity influences the level of TOT. Author in ${ }^{(19)}$ concluded that the training design leads to learning outcome of training program. Author in ${ }^{(20)}$ concluded that training design should be according to cross cultural needs of trainees, for this diversified instructional methods should be adopted. Using hierarchical regression technique author in ${ }^{(8)}$ concluded that transfer design have significant relation with TOT. They suggest that if the organizations want to enhance TOT the training should be designed in such a way that it can enable their trainees to retain learning over time and then transfer it to their job place. They emphasized that it should be ensured that the training program's contents are related to the trainee's job and ${ }^{(3)}$. Author in ${ }^{(21)}$ concluded that perceived utility of content of training may direct motivation of trainees to develop intention to transfer outcome. Author in ${ }^{(22)}$ said that validity of content of training and its design of transfer both work collectively and improve employee's personal efficacy \& transfer motivation and leads to trainee's personal transfer capacity. They discovered that transfer design and perception about validity of content have a significant correlation. Author in ${ }^{(23)}$ found that training design factors significantly explained $65 \%$ variance in performance of training transfer.

Keeping in view the above works of different researchers, a framework for this research has been established as shown in Figure 1 .Transfer of training is the dependent variable in this study. The independent variables that have influence on the transfer of training are perceived content validity and transfer design.

Literature review indicates that studies signifying relationship between perceived content validity and transfer design with transfer of training, less literature can be found about education department, it brings more research necessity regarding this matter. The purpose of the study is to investigate the impact and relationship between these factors in the teachers training in public sector school of Hyderabad Pakistan.

Accordingly, based on the framework of this study the following hypotheses have been proposed:

\subsection{Hypotheses}

H1a. There is significant relationship between perceived content validity and transfer of training 


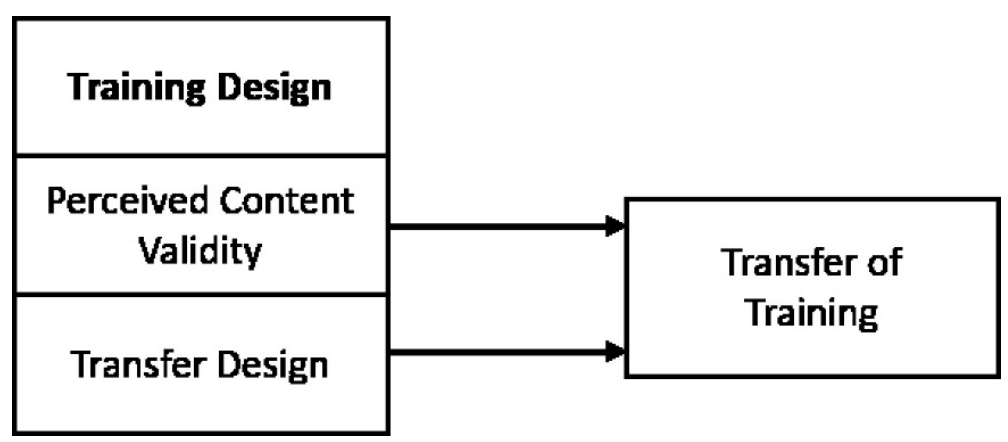

Fig 1. Conceptual framework of this study

H1b. There is a significant impact of perceived content validity on transfer of training. $\mathrm{H} 2 \mathrm{a}$. There is significant relationship between transfer design and transfer of training. H2b. There is a significant impact of transfer design on transfer of training.

\section{Material and methods}

A survey questionnaire with close ended questions was used as research instrument comprising of three sections. First section was about the demographic profile of respondent, in second section there were the items about perceived content validity, and transfer design and the third section was about transfer of training. In section two perceived contents validity and transfer design were measured with modified item, for which sample items were taken from LTSI model ${ }^{(16)}$. Item used in perceived content validity construct were about the content used in training like, books, chart, pictures and illustration and the respondents were asked whether these things were same as used in their classrooms. Item used in Transfer design were about the training activities, illustration and examples used in training, the respondents were asked whether these things helped them in understanding that how these learning can be applied in their classrooms. For third section modified item were added to examine the transfer of training, the sample items were taken from the research of author in ${ }^{(9)}$ which were used to determine the transfer of training. Item used in transfer of training construct were about post training application of the learning in their classrooms and whether this training helped them in improving their teaching skills. All questions were measured on Likert scale ranging from 1 to 5 , these were 1 strongly disagree to 5 strongly agree. The respondents were asked to reply according to their degree of agreement with each statement present in the instrument. Primary data was collected from teachers of public sector school from Hyderabad Pakistan. Total 550 questionnaires were distributed for this study from which 520 were returned back the response was $94.55 \%, 20$ questionnaires were excluded due to incomplete entries, therefore only 500 (i.e. 91\%) questionnaires were considered for analysis which were completely filled. To reduce biasedness, the respondents were ensured that the collection of data and information about their profile is for this research is solely for academic purpose and their responses will remain confidential. The population of this study were public sector school teachers from Hyderabad, Pakistan. There are a total of 8640 public sector teachers in Hyderabad, Pakistan including 4485 male teachers i.e. (51.91\%) and 4155 females i.e. (48.09\%) teachers ${ }^{(24)}$.

Sampling: Simple random technique has been selected for this research as it may be the best, because all units of population may have equal chance for being selected ${ }^{(25)}$. The sample size was calculated using the rule of thumb formula proposed by ${ }^{(26)}$, according to them in multiple regression the minimum preferred sample size is 50 samples and preferably 100 for many research conditions. To make most authentic results a sample size of 500 has been selected for this research.

$\mathrm{KMO}$ values calculated for all variables in this research are above .80 this confirms the adequacy of sample size.

\subsection{Model of Study}

$\mathrm{TOT}=\mathrm{C}+\mathrm{B} 1 \mathrm{PCV}+\mathrm{B} 2 \mathrm{TD}+\mathrm{e} \quad(1)$

Whereas,

TOT (Transfer of training), PC (Perceived Content Validity) and TD (Transfer Design) 


\section{Results and Discussion}

\subsection{Results}

\subsubsection{Descriptive analysis}

Demographic information about respondents

Total number of participative trainee teachers was 500, in which the frequency of male participants was 257 and female was 243 which is almost equal i.e. $51.4 \%$ and $48.6 \%$ respectively. Participants from different age group were 32 from 21 to 30 years, 122 from 31 to 40 years, 256 from 41 to 50 years and 90 from 51 to 60 years. It is clear that most of the teachers are from the group of 41 to 50 years (total 51.2\%). Among trainee teachers 425 teachers were unmarried, 66 were un-married and 9 were widow or widower, most of the teachers were married. Most of them possess master degree (total 262) followed by graduate $=195$, intermediate $=28$, matriculates $=10$ and M.Phil $=5$. Most of the teacher were from primary school Level i.e. 318 from primary, 127 from Middle, 51 from high and 4 from higher secondary school. This proportion is according to the proportion of total schools in each level.

\subsubsection{Exploratory Factor Analysis}

The Exploratory Factor Analysis (EFA) was applied for each studied variable individually for both dependent variable and independent variables as depicted in Table 1 . EFA is applied for ensuring the reduction of item in each construct upto a significant level ${ }^{(26)}$.

\section{Factor analysis of independent variables}

All 10 items of independent variables i.e. perceived content validity and transfer design construct showed the factor loading is greater than cut-off value 0.35 . The Eigenvalue found to be greater than 1, the total variance explained is $61.19 \%$ and $61.60 \%$ respectively. The KMO value found to be 0.804 and 0.845 which is greater than 0.50 and the level of significance (p-value) all of the above mentioned variables found to be less than 0.50 . These results of exploratory factor analysis confirmed that further statistical test may now be applied for analysis.

\section{Factor analysis of dependent variable}

Factor analysis of dependent variables i.e. transfer of training (ToT). All 5 items of this construct showed that the factor loading is greater than cut-off value 0.35 . The Eigenvalue found greater than 1 , the total variance explained is $60.29 \%$. The KMO value found to be 0.833 which is greater than 0.50 and the level of significance (p-value) of the above mentioned variables is less than 0.50 . These results of exploratory factor analysis confirmed that further statistical test may now be applied for analysis, Cronbach's alpha was checked for reliability and each variable was found to be above cutoff value ${ }^{(26)}$.

Table 1. Exploratory Factor Analysis

\begin{tabular}{|c|c|c|c|c|c|c|c|}
\hline \multicolumn{8}{|c|}{ Independent Variable } \\
\hline Construct & Items & Factor loading & Eigen-value & Total Variance explained & KMO Value & Sig. Level & Cronbach's alpha \\
\hline \multirow{6}{*}{$\begin{array}{l}\text { Perceived } \\
\text { content } \\
\text { validity } \\
(\mathrm{PCV})\end{array}$} & PCV 1 & .729 & & & & & \\
\hline & PCV 2 & .828 & & & & & \\
\hline & PCV 3 & .871 & 3.06 & 61.19 & .804 & $.000^{* *}$ & 0.840 \\
\hline & PCV 4 & .772 & & & & & \\
\hline & PCV 5 & .697 & & & & & \\
\hline & TD 1 & .811 & & & & & \\
\hline \multirow{4}{*}{$\begin{array}{l}\text { Transfer } \\
\text { Design } \\
\text { (TD) }\end{array}$} & TD 2 & .825 & & & & & \\
\hline & TD 3 & .799 & 3.08 & 61.60 & .845 & $.000^{* *}$ & 0.842 \\
\hline & TD 4 & .793 & & & & & \\
\hline & TD 5 & .688 & & & & & \\
\hline \multicolumn{8}{|c|}{ Dependent Variable } \\
\hline \multirow{5}{*}{$\begin{array}{l}\text { Transfer of } \\
\text { Training } \\
\text { TOT) }\end{array}$} & TOT 1 & .754 & & & & & \\
\hline & TOT 2 & .810 & & & & & \\
\hline & TOT 3 & .842 & 3.02 & 60.29 & .833 & $.000^{\star *}$ & 0.833 \\
\hline & TOT 4 & .732 & & & & & \\
\hline & TOT 5 & .738 & & & & & \\
\hline
\end{tabular}




\subsubsection{Correlation}

Using Pearson correlation coefficient, a strong correlation was found between transfer design and transfer of training, $r=0.637$ at significant level $\mathrm{p}<.01$. A moderate correlation $\mathrm{r}=0.474$ at significant level $\mathrm{p}<.01$ was found between Perceived content validity and transfer of training. Perceived content validity and Transfer design were also found to be strongly correlated with each other with $r=.621$ at significant level $p<.01$

\subsubsection{Regression}

Table 2. Results to summarize the multiple regression analysis

\begin{tabular}{lllll}
\hline Dependent variable & Independent variable & Value of Beta (Standard coefficient) & Sig. Value & Collinearity Statistics \\
\hline \multirow{2}{*}{ Transfer of Training } & & & VIF \\
& Perceived Content Validity & .127 & $.004^{* *}$ & 1.629 \\
& Transfer Design & .558 & $.000^{* *}$ & 1.629 \\
Adjusted R-square & .413 & & & \\
\hline
\end{tabular}

Note: ${ }^{*}$ Significance at 0.05

In coefficient Table 2, two imported values are depicted, i.e. the beta value and p-value. The beta value usually determines the relationship between dependent and independent variables, while p-value shows the significance level. In this table transfer design is found to have a positive and significant relationship with Transfer of training (the dependent variable and perceived content validity also shows a positive and significant relationship with TOT). In the right most column of the table value of variance inflation factor VIF is depicted. The VIF measure is normally used to check the problem of multicollinearity which may occur if high level of correlation exists between two or more variables. It means that if multicollinearity increases it will complicate the variance interpretation because it will become more difficult to determine any single variable effect due to their relationship ${ }^{(26)}$. A very large VIF value $(\mathrm{VIF}>10)$ and very small value $(\mathrm{VIF}<0.10)$ indicates the existence of high collinearity (ibid). Therefore, in this research no problem of collinearity was found.

The coefficient Table 2 depicts that both studied independent variables i.e. Perceived content validity (PCV) and Transfer Design (TD) have a positive and significant impact on the dependent variable i.e. Transfer of Training (TOT)

In Table 2 , the $b$ coefficient of Perceived content validity is .127 with a significant value $\mathrm{P}<.05$.

In Table 2 , the $\mathrm{b}$ coefficient of Transfer design is .558 with a significant value $\mathrm{P}<.05$.

\subsubsection{Hypothesis Testing}

Followings are the results of hypotheses testing..

\section{Hypothesis testing}

H1a: A moderate correlation $\mathrm{r}=0.474$, with a significant value $\mathrm{p}<.001$ was found between Perceived content validity and transfer of training. Hypothesis accepted.

H1b: b Coefficient of Perceived content validity was .127 with a significant level $\mathrm{P}<.05$ was found. Hypothesis accepted.

H2a: A strong correlation found between transfer design and transfer of training, $r=0.621$, with a significant value $\mathrm{p}<.001$. Hypothesis accepted.

H2b: b Coefficient of Transfer design is .558 with a significant level $\mathrm{P}<.05$ was found. Hypothesis accepted.

\subsection{Discussion}

It is indicated by the results of this study that perceived content validity and transfer design are related and influence transfer of training. The results of this study are similar to previous studies which also concluded that training transfer is predicted by content validity and transfer design. Author in ${ }^{(19)}$ found that the outcome of training program is influenced by training design. Author in ${ }^{(1)}$ found that training design factors influence the transfer of training. Author in ${ }^{(8)}$ concluded that transfer design predicted transfer of training significantly. Author in ${ }^{(3)}$ said that training design plays a significant role in transfer of learning. The significant correlation between transfer of training and perceived content validity and transfer design indicates that with any increase in these factors, it may lead to increase in transfer of training. The findings of this study showed that perceived content validity and transfer design have significant correlation and impact on transfer of training in public sector schools in Hyderabad, Pakistan. Transfer design with beta value $=.558$, was the strongest factor that highly influence the transfer of training. The regression onto independent variables yielded an Adjusted R-Square $=.413$, at a significant level $\mathrm{p}<0.05$. Means that these two independent variables explained $41 \%$ variance in regression model. These findings suggest that if the trainee 
teachers perceive that the content of training like books taught, the charts, pictures and illustration used by trainers were as the trainee teachers used in their school and the training activities were same like their class activities, according to their classroom atmosphere and according to their syllabus then it will lead to more transfer of training and the teachers will be able to transfer their learning in their classrooms. Besides this, if transfer design activities and procedures used by the trainer helps the trainee teacher to know that how these things can be applied in classroom, it could happen if the trainee will be aware that how he/she will use these learnings in the classroom. Varied examples illustrated by trainer will also help understanding trainees about usage in classrooms. The trainer's way of teaching and appropriate material provided to trainees may make the trainees confident in applying the learning in their classrooms. Moreover, the content of training should be easy to apply in order to increase the transfer of training. By the result of this study it is clear that if the content of training and transfer design is according to the real environment of classrooms and specially the material provided, training activities and illustration by the trainers will help in transferring the learning and will help the trainee teacher in accomplishing their jobs in a better way, the skills and knowledge acquired in training program will help trainees in improving the teaching quality.

\subsection{Conclusion}

The findings of this research concludes that if the contents of training are proper, easy and in accordance with the syllabus being taught in classrooms, then the percentage of training transfer may be increased, which may shrink the gap between investment on training and its return. The results of this research may bring improvement in economic development and human development index (HDI). In Pakistan, in order to implement proposed educational policies the economic and political barriers must be removed. To improve unpleasant scenario of education in public sector, the teachers training should be designed in such a way that, it can make the teachers able to retain and transfer their learnings to classrooms. The syllabus related content may direct teachers' motivation to transfer intention and in result their transfer capacity may improve.

\subsection{Managerial implication}

In Pakistan where the education sector is in an unpleasant state, this study will provide a direction to the researchers and practitioners of education department to enhance the effectiveness of training programs by improving the content and relevance of training courses with schools' syllabus in order to increase transfer of learning from training programs to classroom

\subsection{Limitation and Future Research}

This study is limited in such a way that data collected for this research is from public sector school teachers only, therefore, the results of this study cannot be generalized for all school teachers, both from public and private sector. In future private school teachers may also be included in such type of study.

\section{References}

1) BALDWIN TT, FORD JK. TRANSFER OF TRAINING: A REVIEW AND DIRECTIONS FOR FUTURE RESEARCH. Personnel Psychology. 1988;41(1):63-105. doi:10.1111/j.1744-6570.1988.tb00632.x.

2) Devos C, Dumay X, Bonami M, Bates R, Holton E. The Learning Transfer System Inventory (LTSI) translated into French: internal structure and predictive validity. International Journal of Training and Development. 2007;11(3):181-199. doi:10.1111/j.1468-2419.2007.00280.x.

3) Yusof A. The Relationship Training Transfer between Training Characteristic, Training Design and Work Environment. Human Resource Management Research. 2012;2(2):1-8. Available from: http://article.sapub.org/10.5923.j.hrmr.20120202.01.html.

4) Baldwin TT, Ford JK, Blume BD. The State of Transfer of Training Research: Moving Toward More Consumer-Centric Inquiry. Human Resource Development Quarterly. 2017;28:17-28. doi:10.1002/hrdq.21278.

5) Chiaburu DS, Dam KV, Hutchins HM. Social Support in the Workplace and Training Transfer: A longitudinal analysis. International Journal of Selection and Assessment. 2010;18(2):187-200. doi:10.1111/j.1468-2389.2010.00500.x.

6) Doyran F. Research on Teacher Education and Training. Published by Athens Institute for Education and Research. Athens, Greece. Athens Institute for Education and Research. 2012. Available from: https://www.atiner.gr/docs/2012EDUB-INTRO.pdf.

7) Hussain RM. An Empirical study of the relationship between motivation to transfer and transfer of training. Far East Journal of Psychology and Business. 2011;5(1):47-56.

8) Velada R, Caetano A, Michel JW, Lyons BD, Kavanagh MJ. The effects of training design, individual characteristics and work environment on transfer of training. International Journal of Training and Development. 2007;11(4):282-294. doi:10.1111/j.1468-2419.2007.00286.x.

9) Xiao J. The Relationship Between, Organizational Factors and the Transfer of Training in the Electronics Industry in Shenzhen, China. Human Resource Development Quarterly. 1996;1(1):55-73. doi:10.1002/hrdq.3920070107.

10) Todaro MP, Smith SC. Economic Development. 11th ed. and others, editor;Prentice Hall. 2011. Available from: https://www.academia.edu/32239991/ Todaro-Smith.

11) United Nations Educational, Scientific and Cultural Organization. Accountability in education Global Education Monitoring Report 2017/8. 2017. Available from: https://unesdoc.unesco.org/ark:/48223/pf0000259338. 
12) Pardhan H. Action Research for Female Science Teacher development: Case Pakistan. European Journal of Scientific Research. 2005;6(1):46-64.

13) Rahman A, Shiddike M. Agendas for future Training Transfer Research: Pakistan's Perspective. 9. 2019. doi:10.7176/DCS/9-4-06.

14) Kanu Y, Memom M. Elementary Teacher Education; In Pakistan: What Is Needed. Journal of Educational Research. 1994;2(1):29-39. Available from: https://ecommons.aku.edu/pakistan_ied_pdck/116/.

15) Dildar SM, Saif NN, Naz A. Review of Educational Policies of Pakistan: Planning and Implication flows. University of Sargodha/Pakistan. 2016;p. 1-6.

16) III EFH, Bates RA, Ruona WEA. Development of a generalized learning transfer system inventory. Human Resource Development Quarterly. 2000;11(4):333-360. doi:10.1002/1532-1096(200024)11:4<333::aid-hrdq2>3.0.co;2-p.

17) Ahmad AB, Wan M, Kasa ZB, Gessler M, Spootle G. Effectiveness of Learning Transfer in the National Dual Training System (NDTS) in Malaysia. . In: and others, editor. Conference proceeding of Persidangan Kebangsaan Pendidikan Kejuruteraan dan Keusahawanan At: Kota Bahru, Kelantan. 2010;p. 153-164.

18) Chidananda HL, Udayachandra PN. Relationship of Training Design and use of Transfer Strategy with Transfer of Training. International Journal of Management Studies. 2018;V(4(4)):32-32. doi:10.18843/ijms/v5i4(4)/04.

19) Davids A, González J, Garrido MF, González AP, Soto APG. Transfer of learning Motivation, training design and learning conducive work effects. European Journal of Training and Development. 2014;38(8):728-744. Available from: https://doi.org/10.1108/EJTD-03-2014-0026.

20) Lim DH. Training design factors influencing transfer of training to the workplace within an international context. Journal of Vocational Education and Training. 2000;52(2):242-258. doi:10.1080/13636820000200118.

21) Hutchins HM, Nimon K, Bates R, Holton E. Can the LTSI Predict Transfer Performance? Testing intent to transfer as a proximal transfer of training outcome. International Journal of Selection and Assessment. 2013;21(3):251-263. doi:10.1111/ijsa.12035.

22) Kirwan C, Birchall D. Transfer of learning from management development programmes: testing the Holton model. International Journal of Training and Development. 2006;10(4):252-268. doi:10.1111/j.1468-2419.2006.00259.x.

23) Kasim RSR, Ali S. The Influence of Training Design on Training Transfer Performance among Support Staff of Higher Education Institution in Malaysia. International Journal of Innovation Management and Technology. 2011;2(5):377-382. Available from: http://www.ijimt.org/papers/162-M619.pdf.

24) Education and Literacy Department. District Education Profile Hyderabad 2013-14. 2015. Available from: http://www.sindheducation.gov.pk/Contents/ Menu/Sindh\%20Education\%20Profile\%202013-14.pdf.

25) Zikmund WG, Babin BJ, Carr JC, Griffin M. and others, editor. 2009. Available from: https://www.academia.edu/33978482/Business_Research_Method_ -_Zikmund_8th_edition.pdf.

26) Hair JF, Black B, Babin B, Anderson RE. Multivariate Data Analysis. Hall HPP, A US, editors. 2010. Available from: https://is.muni.cz/el/1423/podzim2017/ PSY028/um/_Hair_-_Multivariate_data_analysis_7th_revised.pdf. 